\title{
The Treatment of Snoring in the Armed Forces
}

\author{
JD Hern \\ FRCS
}

\author{
WPL Hellier \\ FRCS(Orl) \\ PF Brasher \\ FRCS,DLO \\ Consultant Otolaryngologist
}

\section{Department of Otolaryngology-Head and Neck Surgery, Frimley Park Hospital, Portsmouth Road, Frimley, Surrey GU16 5UJ}

SUMMARY: Snoring is a common problem, which may have widespread medical and social implications. This is particularly true in the setting of the armed forces where snoring may have significant effects in terms of personal performance, social interaction and security. This paper discusses the general management of snoring in the military environment and in particular the clinical effectiveness of one surgical procedure, uvulopalatopharyngoplasty. In this study, the procedure proves to be an effective surgical option in the management of snoring.

\section{Introduction}

Snoring is a common problem which has many potential consequences both for the individual snorer and others in the immediate environment. The consequences range from causing a minor nuisance to more profound irritation, depending on the loudness and frequency of the snoring. The loudest recorded snore has been measured at 93dBA (1) but even low snoring volumes may provoke aggressive behaviour in partners or collegues and lead to discord. There are also obvious implications in the field, especially if surveillance is to be undertaken. Persistent snorers often have unrefreshing sleep particularly if the snoring is associated with obstructive sleep apnoea syndrome (OSAS). However there is now evidence that even benign snoring in the absence of any significant sleep apnoea may be associated with increased daytime sleepiness and reduce work performance (2). This may lead to particular problems in carrying out military duties. If these include operational duties, driving or working with machinery, a dangerous situation may arise both for the individual concerned and other personnel.

OSAS is divided into mild, moderate and severe forms depending on the number of 10 second or greater apnoeas that are present per hour, (mild 5-20, moderate 20-40 and severe $>40$ ) as recorded by a formal sleep study (polysomnography). Patients with severe obstructive sleep apnoea are at risk of chronic respiratory problems and this group of patients needs to be identified. OSAS sufferers with group 2 DVLA licences (public service and heavy goods vehicles) must cease driving, until it has been confirmed by a specialist that their condition is adequately treated. Depending on the methodology used, the accident rate in patients with OSAS is 5 to 10 times normal (3). The specific management of OSAS is not considered further in this article.

The initial management of snoring is often conservative and may be carried out at local medical unit level. Simple but important measures include weight reduction, decreasing alcohol and cigarette consumption, regular exercise and alteration in the sleeping posture. Many patients and partners report that sleeping on the side seems to be associated with less snoring than sleeping on the back. In addition any problems with the nasal airway must be addressed. In particular rhinitis should be treated with a topical nasal steroid. The nasal airway can sometimes be improved with an adhesive nasal strip applied across the skin of the bridge of the nose. This is designed to increase the nasal patency by flaring the nasal alae. An alternative nasal splint device which fits into the nostrils can be used, but this has been associated with some excoriation of the nasal vestibule. Other measures include the use of an intraoral splint which advances the mandible from the tongue base. Although sometimes effective, there have been problems with associated temporomandibular joint dysfunction and these devices need to be supervised by a department of maxillofacial surgery.

If these conservative measures prove ineffective the serviceman should be referred for a specialist opinion. Several different surgical approaches have been used in the management of snoring. If there is significant symptomatic nasal obstruction and a deviated nasal septum, this can be corrected by performing a septoplasty. However usually the snoring is emanating from the level of the soft palate and it is this region which needs to be addressed surgically.

This paper studies the results of uvulopalatopharyngoplasty on 14 military personnel and also discusses other surgical options in the management of snoring.

\section{Patients and Methods}

Fourteen members of the armed forces who continued to snore

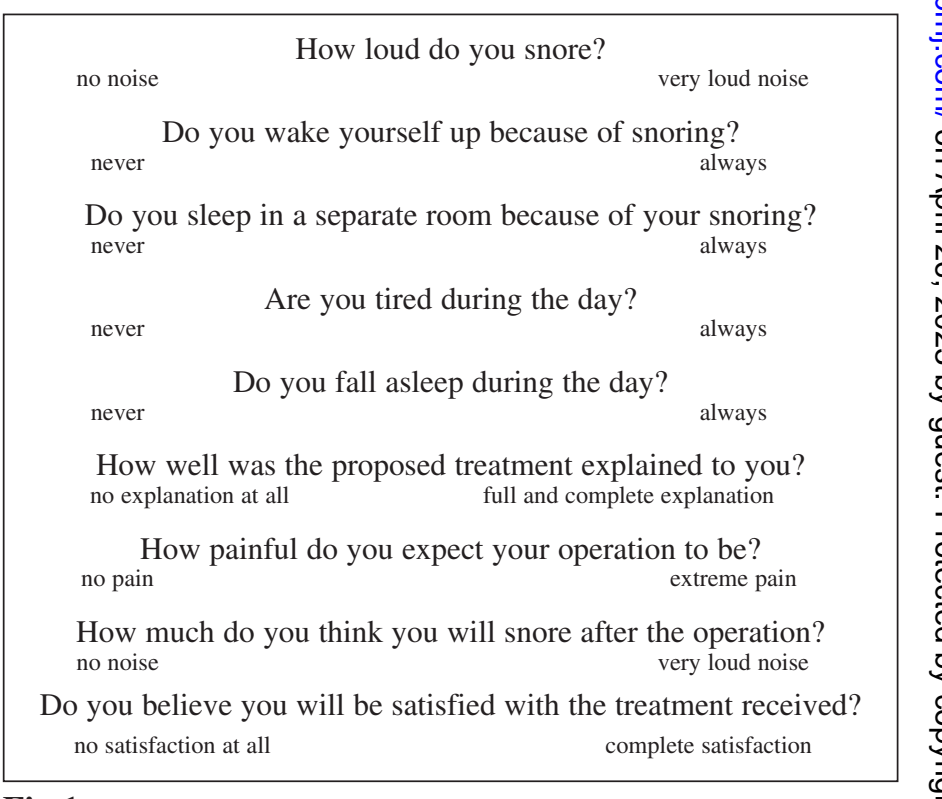

Fig 1. 


$$
\begin{gathered}
\text { no noise } \\
\text { never }
\end{gathered}
$$$$
\text { How loud do you snore? }
$$

very loud noise

Do you sleep in a separate room because of your snoring? never always

Are you tired during the day?

never

Do you fall asleep during the day?

never$$
\text { always }
$$

$$
\text { always }
$$

How well was the proposed treatment explained to you? no explanation at all full and complete explanation

How painful was your operation?

no pain extreme pain no noise How much do you snore since the operation?

Are you satisfied with the treatment received?

no satisfaction at all complete satisfaction

Fig 2.

despite conservative measures were enrolled into the study. Each patient was asked to complete questionnaires pre-operatively and six months postoperatively (Figs $1 \& 2$ ). The questionnaires were adapted from those used by Vukovic and Hutchings in a study on snoring treated by an alternative technique called laser assisted uvulopalatoplasty (4).

There are questions aimed both at the severity of the snoring and the nature of the procedure undertaken. Two additional questions were included in the questionnaire as these were felt to be important in a military environment. These were as follows: are you tired during the day and do you fall asleep during the day? In addition a question on the general satisfaction with the procedure was included. Each patient was asked to mark a standard visual analogue scale and the results pre and post uvulopalatopharyngoplasty were assessed with a paired students test.

\section{Results}

Of the 14 patients, all were male. Their ages ranged from 22 to 49 years, the average age being 29 years. Table 1 shows the mean pre and post operative values for each question obtained from the visual analogue scales and $\mathrm{p}$ values derived from a paired students t test. Significance was taken at a p value of $<0.05$.

There have been significant reductions in the loudness of snoring $(p<0.001)$, waking because of snoring $(p<0.001)$, tiredness during the day $(\mathrm{p}<0.001)$, and falling asleep during the day $(\mathrm{p}=0.02)$ following uvulopalatopharyngoplasty. There is not a significant fall in the number of patients sleeping in separate

Table 1

\begin{tabular}{|lccc|}
\hline & $\begin{array}{c}\text { Mean } \\
\text { pre op }\end{array}$ & $\begin{array}{c}\text { Mean } \\
\text { post op }\end{array}$ & $\begin{array}{c}\text { P } \\
\text { value }\end{array}$ \\
\hline Loudness of snoring & 8.2 & 2.5 & $<0.001$ \\
\hline Waking because of snoring & 4.9 & 1.6 & $<0.001$ \\
\hline Sleeping in separate rooms & 4.7 & 2.5 & 0.06 \\
\hline Tiredness during the day & 5.3 & 2.4 & $<0.001$ \\
\hline Falling asleep during the day & 2.9 & 1.7 & 0.02 \\
\hline Explanation of treatment & 8.3 & 8.4 & 0.65 \\
\hline Pain due to operation & 7.7 & 8.4 & 0.19 \\
\hline Snoring reduction after operation & 2.5 & 2.4 & 0.70 \\
\hline Satisfaction with treatment & 8.8 & 8.5 & 0.31 \\
\hline
\end{tabular}

rooms since the surgery $(\mathrm{p}=0.06)$. Patients seem to indicate that the explanations given pre-operatively tended to be full and complete (mean 8.3), with no significant difference with the preoperative explanation patients feel should be given, having had the operation (mean 8.4, $\mathrm{p}=0.65$ ). In particular, patients were adequately warned about the degree of postoperative pain, with pain expectation (mean 7.7) not significantly different from the amount of pain actually experienced (mean $8.4, \mathrm{p}=0.19$ ). Patient expectation in terms of the amount of snoring present after the operation was towards the 'no noise' end of the visual analogue scale (mean 2.5) and this was matched by the actual postoperative result at six months (mean $2.4, \mathrm{p}=0.7$ ). In general each patient believed that they would be satisfied with the results of their surgery (mean 8.8) and this was indeed the case when viewed postoperatively (mean $8.5, \mathrm{p}=0.31$ ).

\section{Discussion}

Uvulopalatopharyngoplasty was originally developed in Japan in the 1950 s by Ikematsu (5). However it was not widely practised until Fujita et al described the technique in the American literature in 1981 (6). This technique was modified by Simmons et al in 1983 (7) and there have been several minor modifications since. The standard procedure now used involves removal of the tonsils, or if these are absent the tonsillar fossae are deepithelialised. The mucosa of the anterior and posterior faucial pillars is trimmed and an appropriate amount of soft palate is then removed. This depends on the dimensions of the palate, but seldom exceeds $1.5 \mathrm{~cm}$. The pillars are sewn together to tighten the mucosa of the posterior pharyngeal wall and the palatal wound may be sutured either fully or at the lateral margins.

In the literature, uvulopalatopharyngoplasty has produced many reports of satisfactory results. Pelausa et al reported elimination or improvement in snoring in $75.9 \%$ of patients (8) for example. Our smaller study again suggests a significant improvement in snoring, together with improvements in other parameters such as waking up due to snoring, tiredness during the day and falling asleep during the day. All these parameters are important in a military environment, particularly the reduction in daytime somnolence which could lead to a safer working environment.

However uvulopalatopharyngoplasty should not be undertaken without full explanation of the operation and potential postoperative complications. The technique certainly has several disadvantages. It can be disfiguring as the uvula is removed, there is a risk of postoperative haemorrhage, the postoperative pain experienced can be severe and there is a risk of velopharyngeal insufficiency with postoperative nasal regurgitation. In addition there is a potential failure rate in terms of snoring reduction, especially if the snoring is caused by other abnormalities in the upper aerodigestive tract. This problem may be reduced by performing a pre-operative sleep nasendoscopy to confirm the snoring is localised to the soft palate and to exclude hypopharyngeal and tongue base collapse as an aetiological factor. A further potential problem with uvulopalatopharyngoplasty is that although results are often satisfactory six months postoperatively, longer term results are more variable.

This has led other surgeons to develop alternative procedures designed to overcome some of the disadvantages associated with the procedure. In 1993 Ellis described a palatal stiffening procedure called laser palatoplasty (9). Using the NdYAG laser a central longitudinal strip of mucosa is removed from the soft palate, which heals by fibrosis leading to stiffening of the palate. This reduces the amount of palatal flutter, one of the mechanisms involved in snoring. In a recent study, Richardson and Pritchard compared the outcome of uvulopalatopharyngoplasty and laser 
palatoplasty using the Glasgow Benefit Inventory, a validated questionnaire about global health status. Both groups had similar improvements in snoring 15 months postoperatively (10). In 1990 and thereafter another technique was described by Kamami called laser assisted uvulopalatoplasty (11). This treatment may be administered under local anaesthesia using a $\mathrm{CO}_{2}$ laser, delivered by a specially designed hand piece which incorporates a backstop. Full thickness vertical incisions are made in the soft palate on both sides of the uvula, which is then partially excised. The procedure may be repeated several times to produce the desired length of soft palate and uvula. More recently general anaesthesia has been used to complete a single stage procedure. This also allows prominent tonsils to be removed and prominent posterior pharyngeal pillars to be trimmed. Vukovic and Hutchings (4) reported a six month follow up of patients who had undergone laser assisted uvulopalatoplasty. They concluded that the procedure resulted in an overall improvement in snoring and an attendant improvement in lifestyle.

A new procedure called somnoplasty has recently been described by Powell et al (12). The technique uses radiofrequency thermal ablation in which a generator produces low energy current and via an electrode placed into the soft palate, heats the tissue to between 70 and $90^{\circ} \mathrm{C}$. This causes a submucosal lesion in the palate which is gradually resorbed leading to tissue volume reduction and collagen contraction. This stiffens the palate and reduces its propensity to vibrate. The technique may be performed under local anaesthesia and apparently causes minimal postoperative pain. However there are no long term follow up trials as yet.

Despite the information discussed above, it should be remembered that the reporting of snoring in patients undergoing surgery may be inaccuarate. It has been suggested that patients may report high levels of improvement to allay their own fears of possible further treatment and postoperative discomfort. For this reason, the postoperative improvement from the patient's partner and postoperative polysomnography (sleep study) should be used as objective findings (13). In this regard Kantsonis et al report that only $60 \%$ of patients undergoing snoring surgery would in retrospect have the same treatment again (14). The importance of the conservative measures mentioned in the introduction should therefore be stressed once again. Any member of the armed forces who is concerned about snoring should pay particular attention to achieving their ideal weight as judged by the body mass index. Only if reasonable efforts have been made in this regard should consideration be given to operative intervention. At this stage the patient needs to be informed of the potential consequences of whichever type of surgery is contemplated, preferably with their partner present. It is to be hoped that with all the information available to them, partners and collegues may be more sympathetic to the plight of the snorer if surgery is to be undertaken.

\section{Conclusion}

The management of snoring in the armed forces is an important issue. Conservative treatments administered at medical unit level are to be encouraged. However in an appropriately informed patient, operative intervention can be successful. This study has confirmed the effectiveness sof uvulopalatopharyngoplasty in a military practice.

\section{References}

1. Shehab Z, Robin P. Comparison of uvulopalatophayrngoplasty and laser palatoplasty for snoring. Clin Otolaryngol 1997; 22: 158-462.

2. Haraldsson P, Carenfelt C, Lynsdahl M, Tornos J. Long term effect of uvulopalatopharyngoplasty on driving performance. Arch Otolaryngol Head Neck Surg 1993; 121: 90-91.

3. BENNETT L. Morbidity and mortality in OSA. Fact or fiction. ENT News 1999; vol 8 no 2:15.

4. Vukovic L, Hutchings J. Patient evaluation of LaserAssisted Uvulopalatoplasty. J Otolaryngol 1996; 25: 404407.

5. IKEMATSU. Study of snoring. 4th report. J Jap Otol-RhinolLaryngol 1964; 64: 434-435.

6. FuJita S, CONWAY W, Zorick F, Roth T. Surgical correction of anatomic abnormalities in obstructive sleep apnoea syndrome: uvulopalatopharyngoplasty. Otolaryngol Head Neck Surg 1981; 89: 923-924.

7. Simmons F, Guilleminault C, Silvestri R. Snoring and some obstructive sleep apnoea, can be cured by oropharyngeal surgery. Arch Otolaryngol 1983; 109: 503507.

8. Pelausa E, Tarshis L. Surgery for snoring. Laryngoscope 1989; 99: 1006-1010.

9. Ellis P, Ffowcs Williams J, ShNeERSON J. Surgical relief of snoring due to palatal flutter: a preliminary report. Ann R Coll Surg Engl 1993; 75: 286-290.

10. Richardson H, PRitchard A. Comparing the outcome of two surgical treatments for snoring using a patient-orientated measure of benefit. Clin Otolaryngol 1997; 22: 459-462.

11. Kamami Y-V. Laser $\mathrm{CO} 2$ for snoring. Preliminary results. Acta Otorhinolaryngol Belg 1990; 44: 451-456.

12. Powell N, Riley R, Troell R, Li K, Blumen R, GuilleminautT C. Radiofrequency volumetric tissue reduction of the palate in subjects with sleep disordered breathing. Chest 1998; 113: 1163-1174.

13. Kotecha B, Paun S, Leong P, Croft C. Laser assisted uvulopalatoplasty: an objective evaluation of the technique and results. Clin Otolaryngol 1998; 23: 354-359.

14. Kantsonis G, Friedman W, Rosenblum B. The surgical treatment of snoring: a patient's perspective. Laryngoscope 1990; 100: 138-140. 